\title{
Planejamento urbano e vida cotidiana em cidades e áreas patrimoniais
}

\section{Urban planning and everyday life in historical cities and patrimonial areas}

\author{
Wendel Henrique \\ Universidade Federal da Bahia
}

\begin{abstract}
Resumo: Este texto traz reflexões sobre as contradições existentes entre os processos de planejamento e ações implementadas em cidades históricas ou áreas intraurbanas históricas, tombadas institucionalmente pelo IPHAN (Instituto do Patrimônio Histórico e Artístico Nacional), na tentativa de preservação do acervo cultural material e imaterial destas cidades. O conjunto de ações implementadas nestas localidades acaba por petrificar os espaços da cidade (formas) e museificar o cotidiano (conteúdos). Os processos de produção do espaço implicam em mudanças e movimentos constantes tanto no plano das formas (morfologia) quanto dos conteúdos (funções) e, portanto, o tombamento, apesar da necessidade de preservação e conservação dos patrimônios urbanos, podem retirar destas cidades ou áreas tombadas os movimentos da vida cotidiana que preenchem e animam as formas, que permanecerão na cidade, mas esvaziadas de conteúdos, em uma cenarificação do espaço. Pensarmos planejamento de áreas patrimoniais e vida cotidiana é uma tarefa complexa, que ainda necessita de um aprofundamento teórico e técnico, pois o planejamento é o conjunto de normas implementadas em um espaço (a cidade se torna o território das normas), mas a cidade é também o lugar onde se desenrolam os acontecimentos espontâneos da vida cotidiana, aquelas ações e práticas que fogem das normas e possibilitam a riqueza e diversidade de possibilidades de vida nas cidades.
\end{abstract}

Palavras-chave: Planejamento urbano. Vida cotidiana. Cidades históricas. Patrimônios urbanos.

\begin{abstract}
This paper brings some reflections on the contradictions that are embedded in urban planning processes in historical towns or historical intra-urban areas, as they are defined by IPHAN (Brazilian Institute of Historical and Artistic Heritage) as an attempt to preserve the material and immaterial cultural heritage of cities or localities. The set of the implemented actions in these locations petrifies the space of the city (forms) and promotes the museumisation of everyday life (contents). Hereby, the processes of spatial production imply in changes and constant movements of forms (morphology) and contents (functions) and, therefore, the patrimonialization of urban heritage can isolate - despite a need for preservation and conservation - cities or areas from the movements of everyday life. While everyday life fills and animates urban forms, the conservation measures can also reduce these spaces to simple sceneries. Reflecting on urban planning in patrimonial areas and everyday life is a complex task, which still requires a deeper theoretical and technical understanding, as planning must be interpreted as a normative set of standards that are implemented on a wider range in a single area (the city becomes the territory of rules). But the city is also the place where spontaneous events are taking place in everyday life; these are actions and practices that go beyond the rules and thus pave way to the richness and diversity of urban life in the city.
\end{abstract}

Keywords: Urban planning. Everyday life. Historical cities. Urban heritage. 


\section{INTRODUÇÃO}

A quem em nossa terra percorre tais e tais zonas, vivas outrora, hoje mortas, ou em via disso, tolhidas de insanável caqueixa, uma verdade, que é um desconsolo, ressurte de tantas ruínas: nosso progresso é nômade e sujeito a paralisias súbitas. Radica-se mal. Conjugado a um grupo de fatores sempre os mesmos, reflue com eles duma região para outra. Não emite peão. Progresso de cigano, vive acampado. Emigra, deixando atrás de si um rastilho de taperas.

(...) Mal a uberdade se esvai, pela reiterada sucção de uma seiva não recomposta, como no velho mundo, pelo adubo, o desenvolvimento da zona esmorece, foge dela o capital - e com ele os homens fortes, aptos para o trabalho. E lentamente cai a tapera nas almas e nas coisas.

(...) Ali tudo foi, nada é. Não se conjugam verbos no presente. Tudo é pretérito.

Umas tantas cidades moribundas arrastam um viver decrépito, gasto em chorar na mesquinhez de hoje as saudosas grandezas de dantes.

(...) Erguem-se por ali soberbos casarões apalaçados, de dois e três andares, sólidos como fortalezas, tudo pedra, cal e cabiuna; casarões que lembram ossaturas de megateiros donde as carnes, o sangue, a vida, para sempre refugiram.

(...) São os palácios mortos da cidade morta.

Cidades Mortas - Monteiro Lobato (1972) constituiu a primeira rede urbana no Brasil, impulsionada pelo papel de destaque na economia colonial e mesmo durante o período imperial. Os vínculos entre as cidades e o mundo rural sempre foram marcantes na paisagem e na constituição dos lugares.

Dentre os núcleos "urbanos" destacados neste processo de constituição da rede urbana do Recôncavo, Cachoeira sempre apresentou importância em diversas escalas de análise. Regionalmente desempenhava papel central no sistema de transporte flúvio-marítimo, em função de seu porto no baixo curso do Rio Paraguaçu, já próximo a sua foz, na Baía de Todos os Santos. Os armazéns localizados nas margens do Paraguaçu eram marcantes na paisagem urbana e simbolizavam o papel econômico da cidade como entreposto comercial entre o litoral e o "sertão" brasileiro. Politicamente, Cachoeira era um importante centro baiano, exercendo função primordial no processo de Independência da Bahia, tendo recebido o título de "Cidade Heróica".

Os aspectos políticos e econômicos que garantiam a centralidade de Cachoeira e favoreciam sua articulação regional e nacional preencheram as formas urbanas até

As cidades do Recôncavo Baiano se originam com o processo de ocupação do território brasileiro e se configuram como aglomerações citadinas com intensos fluxos e relações com as culturas agrícolas fumo e cana de açúcar destinadas à exportação e que eram desenvolvidas na região.

Segundo Milton Santos (1959), foi no Recôncavo Baiano que se

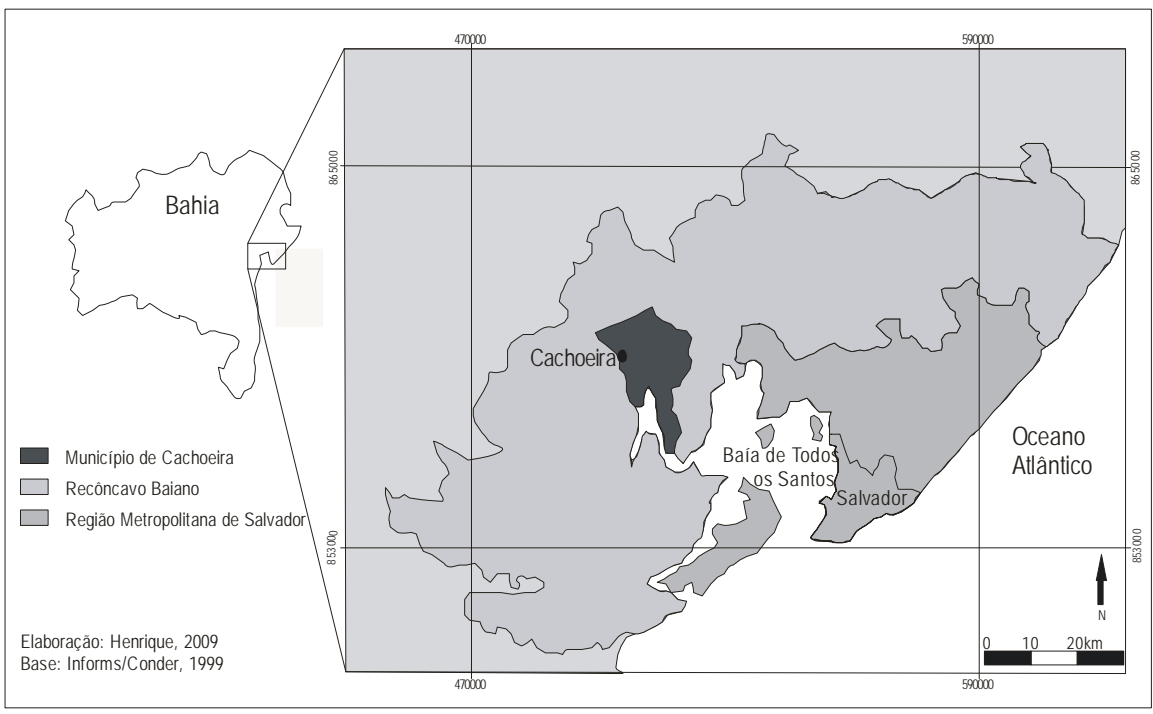

Figura 1 - Localização do Município e da Cidade de Cachoeira 
meados no século XX, quando transformações estruturais no sistema de transporte e na economia levam a redefinições dos papéis e funções das cidades do Recôncavo.

As mudanças na estrutura econômica e no papel de Cachoeira na rede urbana regional estão fortemente atreladas à alteração no padrão de transporte de mercadorias, com a opção pela modalidade rodoviária em detrimento ao transporte marítimo/fluvial (realizado pelos vapores e saveiros que faziam seus percursos através da Baía de Todos os Santos e pelo Rio Paraguaçu) e ao transporte ferroviário (que tinha em Cachoeira um importante entroncamento). As rodovias que passam a ligar o litoral ao interior (BR's 324 e 101) têm seus trajetos exteriores e distantes do tecido urbano de Cachoeira, implodindo as funções articuladoras da cidade com suas congêneres regionais e estaduais.

Colaborando com o entendimento para a mudança no papel exercido por Cachoeira na articulação regional, Costa Pinto (1998, p. 123) escreve que:

a decadência da senhorial cidade de Cachoeira e a ascensão de Cruz das Almas, que é hoje [1952] o chef-lieu do Recôncavo Fumageiro, indicam, expressivamente, as fases de um processo de sucessão histórica e ecológica, para o qual, mais recentemente, outros fatores de renovação, como o caminhão e a rodovia, também contribuíram decisivamente.

Para completar o processo de estagnação do Recôncavo Canavieiro e Fumageiro, também na metade do século XX, ocorre a descoberta de petróleo na área do Recôncavo mais próxima de Salvador. O desenvolvimento da cadeia produtiva do petróleo, indo além da extração e passando pelo refino e pelo transporte, trouxe profundas mudanças na articulação do sistema urbano, pois toda uma rede de infraestruturas é criada para atender as exigências da indústria petrolífera, isolando as áreas tradicionais. Grandes parcelas das populações das áreas canavieiras e fumageiras foram atraídas para as cidades vinculadas às atividades petrolíferas, como Candeias, São Francisco do Conde e Madre de Deus.

Em 1971, o IPHAN (Instituto do Patrimônio Histórico e Artístico Nacional) tomba todo o sítio de Cachoeira como Monumento Nacional (Decreto $n^{\circ}$ 68.045, de janeiro de 1971). O tombamento, cujo objetivo era garantir a preservação do acervo material urbano da cidade, também acaba por congelar Cachoeira no momento de grande declínio de suas funções urbanas e de esvaziamento de suas formas construídas, que acabam por se transformar em ruínas.

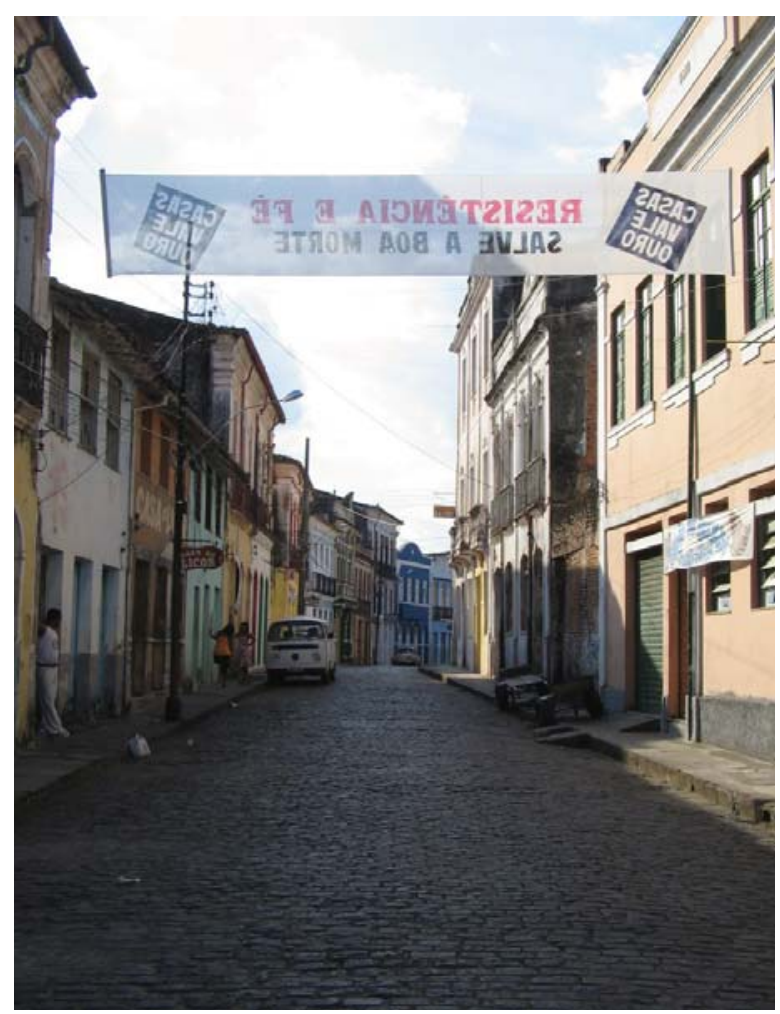

Figura 02 - Uma rua central em Cachoeira. Autor: Henrique, 2006. 


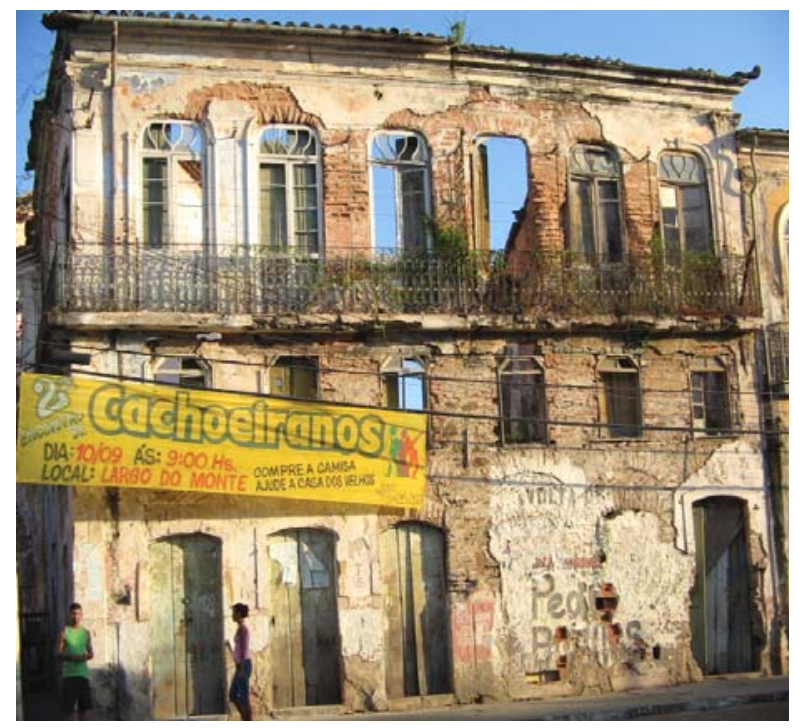

Figura 03 - Casarão em ruínas. Autor: Henrique, 2006

Para superar este processo de estagnação econômica, que perdura por algumas décadas, segundo Henrique (2009), várias ações vinculadas ao planejamento urbano, regional e econômico estão sendo implementadas em Cachoeira, tais como: a instalação da Universidade Federal do Recôncavo da Bahia - UFRB (Ministério da Educação), o Programa de Turismo Étnico (Ministério do Turismo), o PAC Cidades Históricas e o Monumenta (Ministério da Cultura).

A UFRB possui uma constituição multicampi, instalada, a partir de 2005-2006, em 04 municípios do Recôncavo Baiano. Em Cachoeira está instalado o Centro de Artes, Humanidades e Letras, que oferece os cursos de Jornalismo, História, Museologia, Ciências Sociais, Serviço Social e Cinema e Audiovisual.

Os projetos do setor de turismo étnico, vinculados ao patrimônio histórico e cultural (casario colonial, festas e outras manifestações culturais) têm ocasionado modificações na estrutura urbana de vários municípios do Recôncavo, como mais uma ação na tentativa de redinamização das economias locais e regionais. No caso específico de Cachoeira, em função da
Festa da Irmandade de Nossa Senhora da Boa Morte (a Irmandade foi constituída há quase 160 anos exclusivamente por mulheres negras vinculadas ao candomblé), atualmente se desenvolve um projeto de Turismo Étnico, através do Programa de Ação do Turismo Étnico Afro da Bahia, uma parceria entre o Governo do Estado da Bahia e o Ministério do Turismo, cuja dotação orçamentária é da ordem de R\$ 1.245.200,00.

Segundo o Ministério das Cidades (www.cidades.gov.br), "O MCidades vai atuar no PAC Cidades Históricas na requalificação urbana; na infraestrutura urbana e social; e na recuperação de monumentos e imóveis públicos, com o Programa de Reabilitação de Áreas Centrais, da Secretaria Nacional de Programas Urbanos (SNPU). O programa poderá qualificar 173 cidades históricas brasileiras para recuperar seus papéis simbólicos e referenciais da cultura. Além do Ministério das Cidades, participam os Ministérios da Cultura, do Turismo e da Educação, Instituto do Patrimônio Histórico e Artístico Nacional (IPHAN), Eletrobrás, BNDES, Petrobras, CAIXA e Banco do Nordeste (BNB). A previsão é de que todo o investimento seja feito até 2012, com início já neste ano. Essa primeira fase do programa prevê um investimento de R\$ 140 milhões em 32 municípios.". Na Bahia, serão Salvador, Cairu e Cachoeira.

Já o Monumenta, com recursos da ordem de R\$25 milhões é um Programa do Ministério da Cultura para recuperação e preservação do patrimônio histórico em cidades históricas protegidas pelo Instituto do Patrimônio Histórico e Artístico Nacional (IPHAN), com recursos oriundos de financiamento do Banco Interamericano de Desenvolvimento (BID) e o apoio da Unesco (Organização das Nações Unidas para a Educação, Ciência e Cultura). 


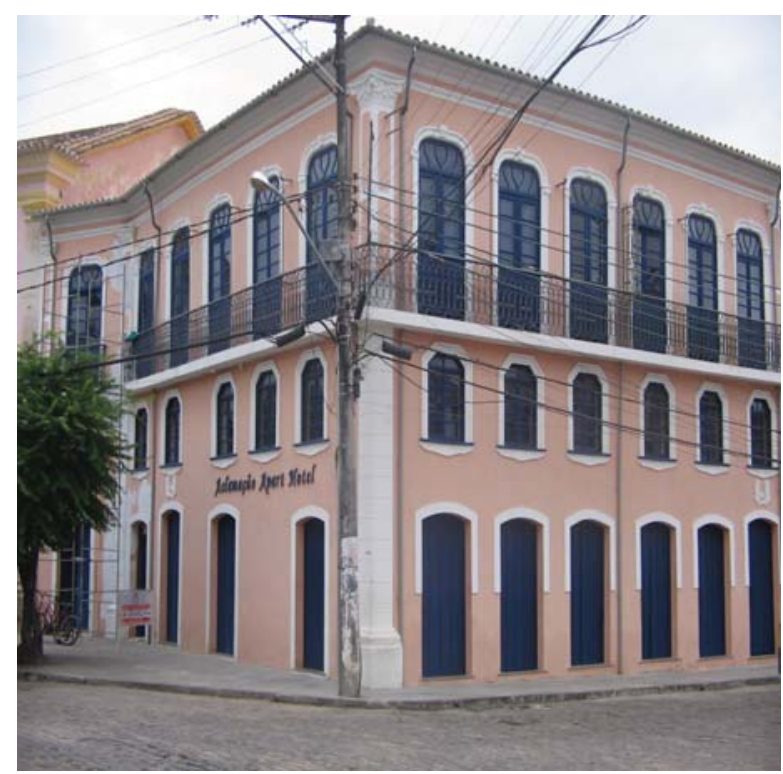

Figura 04 - O casarão reformado (figura 03) e a instalação de um apart-hotel. Autor: Henrique, 2009

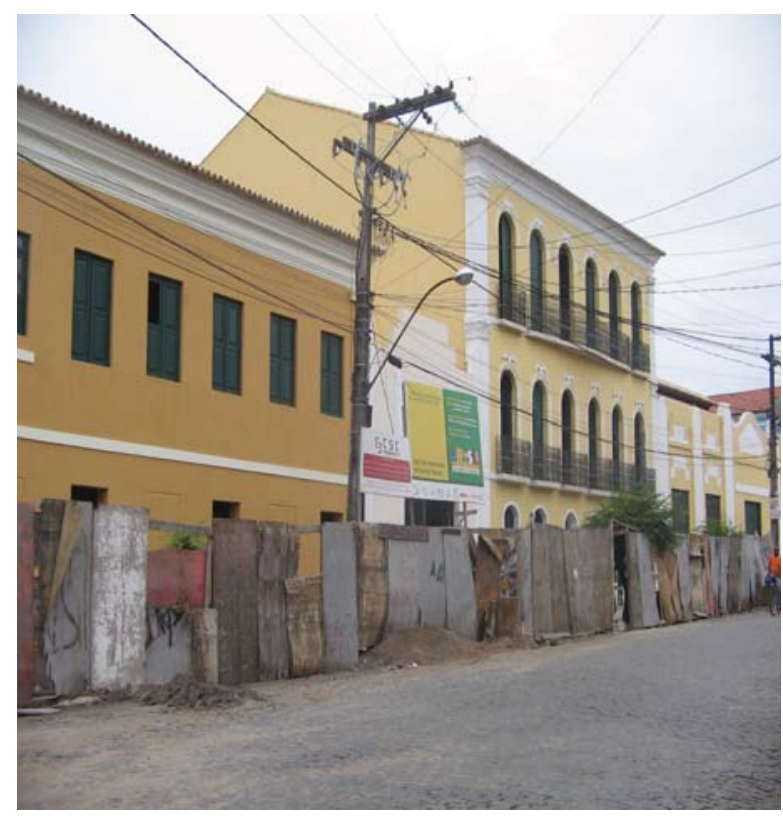

Figura 05 - O quarteirão Leite Alves (antiga fábrica de Charuto) em reforma para receber o CAHL/UFRB.

Autor: Henrique, 2009

\section{A DISCUSSÃO - PRODUÇÃO DO ESPAÇO, COTIDIANO E MUSEIFICAÇÃO DA CIDADE}

As ações planejadas e implementadas em Cachoeira, cidade tombada desde 1971, insere várias contradições. A construção histórica e o acervo são os condicionantes ao tombamento, destinado principalmente as formas que compõe a cidade. As formas são passíveis de serem 'tombadas, congeladas, conservadas, preservadas, recuperadas, refuncionalizadas, requalificadas, petrificadas, museificadas', as formas, pelas suas características de fixos espaciais comportam sua petrificação, vista inclusive como uma possibilidade positiva do planejamento e da gestão das cidades. Entretanto, as formas não são autônomas, possuem apenas consistência material, elas não inserem uma existência, pois a existência é dada pelo conteúdo que anima estas formas, pela vida que se apropria das formas como lugar da casa ou do encontro coletivo, uma construção cotidiana, da qual participam diversos agentes. Segundo Henri-Pierre Jeudy, "conservar já não é uma maneira de pôr fim a algo que ainda está vivo? Isso pode ser visto perfeitamente em cidades onde a reconstrução 'museográfica' de um bairro é a assinatura de sua condenação à morte. $\mathrm{O}$ que mostra a vida de um bairro antigo é sua indeterminação, o jogo de tensões que o percorrem no ritmo de um reajustamento vivido do espaço" (JEUDY, 2005, p. 70).

Se é possível tombar a forma, é possível tombar o conteúdo/existência/cotidiano?

Aqui residem várias possibilidade de resposta a esta pergunta, central nos processos de planejamento e gestão das cidades históricas, ou melhor das cidades com grandes acervos materiais e imateriais, quer seja do ponto vista arquitetônico ou cultural. Afinal, nomear apenas cidades de históricasé negar que toda cidade é histórica, pois toda cidade se realiza como construção coletiva ao longo do tempo, que pode ser o tempo do desenrolar do processo de ocupação do território Brasileiro, como Ouro Preto e Cachoeira, ou o 
tempo das novas formas de urbanização do país vinculadas ao agronegócio da soja, que produzem cidades em 10 anos. Seriam estas cidades novas cidades sem história? Deixando de lado esta questão, retomaremos a idéia do tombamento dos conteúdos.

A princípio podemos responder que não, os conteúdos não são passíveis de serem tombados. Entretanto, na esfera de algumas correntes do planejamento e da gestão cria-se uma ruptura, como podemos tombar metade de algo? Se a cidade é uma forma-conteúdo, não se pode apenas tombar a forma, é necessário tombar a cidade como um todo.

O tombamento dos fluxos implica na tentativa de obstrução de uma característica intrínseca das cidades, do cotidiano e da produção do espaço: o movimento. $\mathrm{O}$ movimento leva à transformação e substituição dos conteúdos, é o fluxo vital que cria a vivacidade do espaço e do próprio cotidiano, afinal o cotidiano não é apenas permanências, ele também é o lugar da mudança. Permanências e mudanças são elementos centrais na construção dos conteúdos. Desta forma, o conteúdo e o cotidiano tombados a força criam uma paralisia da vida, uma "museografia do vivo petrificado e paralisado (...) o mundo deve se tornar um grande museu para que a identidade, a etnicidade, a alteridade não sejam mais do que rótulos, e que a invocação destas últimas sirva sobretudo para o comércio turístico mundial" (JEUDY, 2005, p. 42).

Afinal, a cidade antiga era a cidade da vida antiga; lócus da reprodução da vida a partir das relações historicamente determinadas naquele tempo. $\mathrm{O}$ plano do conteúdo vincula-se a um tempo e as relações sociais e geográficas em determinado recorte do tempo. Além disto, outra observação se faz importante, uma vez que o patrimônio, remanescente de outro período, onde a cidade passava por processos singulares, se insere no processo de produção contemporânea da cidade e do espaço urbano, instaurando um choque de temporalidades e de usos destas formas. Como o fluxo do tempo, o fluxo do conteúdo segue no mesmo curso.

Esta característica do conteúdo esbarra no tombamento completo destas cidades, ricas em patrimônios e, assim, a opção mais rápida e mais barata, lembrando que o planejamento e a gestão das cidades acontecem na esfera da produção capitalista do espaço, é a elaboração de planos que forcem o enquadramento do conteúdo pela forma tombada, tendo como meta, o tombamento completo. Salientamos que essa limitação do movimento na esfera dos conteúdos também passa por algumas correntes do pensamento acadêmico que constroem suas teorias sobre concepções estáticas do cotidiano e da cultura, sempre se referindo ao projeto de futuro como uma cópia de estratégias e ações do passado; ou ainda o confinamento da ruralidade em uma aura de positividades tradicionais em oposição à urbanidade como a materialização da negatividade moderna. Esta discussão é um campo minado repleta de dogmas, ideologias e questões de ordem política.

Jeudy (2005) coloca que o modelo mundial de planejamento e gestão patrimonial vincula-se a uma padronização e homogeneização das intervenções, pensadas na escala do mundo, sem considerar as singularidades e as culturas locais.

No plano das formas, constamos uma teatralização - cenarificação das construções. Neste arremedo de cidade transformada em cenário, a vida acontece numa repetição de gestos teatrificantes do cotidiano local. É comum observamos nas áreas patrimoniais a realização de peças, a filmagem de propagandas e mesmo a realização de festas temáticas. A maneira 
como acontecem as intervenções acabam por criar uma banalização das formas patrimoniais, tudo parece ser previsível e repetido tantas vezes, que todas as fotos são iguais, todas as memórias das construções são iguais, nossos olhos acabam se cansando, pois temos a impressão de que já olhamos tudo aquilo.

A cultura local materializada na produção da forma se esvai, ou em alguns casos, é representada por uma 'pseudo cultura local', passível de ser encenada com atores da 'comunidade' que reconstróem no plano da realização teatral um passado mítico e heróico, de exaltação, às vezes quase natural, do poder de superação das dificuldades de um grupo, instituindo uma 'nova cultura local', agora em consonância com a intervenção do planejamento, que produz uma construção petrificada.

A encenação pública das memórias coletivas passa a ser um roteiro de resgate da memória da cidade? Parece que sim. Em Bento Gonçalves, na Serra Gaúcha, a cada 15 minutos é possível assistir à epopéia italiana, uma saga que conta a história e os costumes (cultura?) das famílias italianas que migraram para o Brasil, tudo isso regado a muito vinho. Em Pomerode, Santa Catarina - área de colonização alemã - após um típico almoço alemão, é possível tirar fotos usando roupas típicas. Tentativas de petrificação dos conteúdos.

Para Jeudy, "os espetáculos patrimoniais são sempre apresentados como 'reconstruções vivas' (...) cada vez que os habitantes de um conjunto de pequenas cidades participam da construção de um espetáculo como este, está garantida uma 'nova encenação' das memórias coletivas. Trata-se de uma situação ideal para conciliar a preservação do patrimônio e o desenvolvimento cultural de uma região. (...) a reconstrução kitsch apresenta-se no mínimo como uma sedutora projeção de diapositivos da grande paródia das me-
Planejamento URBANO E VIDA COTIDIANA EM CIDADES E ÁREAS PATRIMONIAIS

mórias". (JEUDY, 2005, p. 32)

Aqui está algo central, nestas áreas tombadas e de conteúdos e cotidianos mantidos sob as normas da preservação, conservação e da tradição, "os corpos estão destinados a serem estátuas" (JEUDY, 2005, p. 93). Se os corpos estão petrificados em estátuas, as possibilidades de realização plena do cotidiano e da vida também se petrificam, pois o corpo é a forma de subversão das normas impostas pelo planejamento e pela gestão destas áreas tombadas. A ação mais perversa é, portanto, o tombamento dos corpos.

Além disso, "essa mesma ordem simbólica, representada por objetos, monumentos e locais, impõe-se como a aventura de nossa própria inteligibilidade. Produzimos, damos forma, vendemos representações de ordem simbólica, uma vez que o valor simbólico e o valor de mercado se confundem. Este é um dilema da gestão contemporânea dos patrimônios: se o patrimônio não dispõe de um estatuto 'a parte', se ele se torna uma mercadoria como as outras (os bens culturais), perderá seu poder simbólico". (JEUDY, 2005, p.20)

Aqui temos outras contradições. No mundo contemporâneo, os patrimônios não podem ser considerados apenas produtos do mercado e do marketing das cidades, mas não existem programas de 'revitalização', renovação ou recuperação de patrimônios que não os insira nos roteiros turísticos. A presença do patrimônio no mundo, portanto é configura como uma possibilidade turística.

\section{FINALIZANDO - ONDE ESTÁ A CONTRA-RACIONALIDADE?}

Grande parte das ações de planejamento de áreas e cidades tombadas vincula-se à tentativa de 'retirada' do patrimônio do 
fluxo contínuo da cidade, as formas tombadas - preservadas e conservadas - se configuram ilusoriamente sob uma redoma; as intervenções do planejamento retiram a força o patrimônio da cidade. Os corpos tornam-se estátuas e o cotidiano vira uma peça teatral. A imagem negativa predomina, mas dentro dela existem as possibilidades de se pensar e viver o novo, enfim, nas formas e nos conteúdos tombados residem as contra-racionalidades, que podem dar uma nova vida a áreas tombadas.

Se perguntarmos a qualquer turista que visita ou visitou Salvador, se ele foi ao Maciel, se ele conhece o Maciel, provavelmente ouviremos 'não' como resposta. Temos no Maciel de Cima e Maciel de Baixo um caso emblemático de intervenção em uma área tombada da cidade, uma invenção do mundo da mercadoria, um produto afro-baiano-brasileiro que resgata um aparato de tortura e disciplina da sociedade escravagista e o alça a rótulo 'identitário' de uma área da cidade, agora marcado nos mapas turísticos como Pelourinho. A tentativa da ação era manter o 'Pelourinho' como uma imagem da cidade de Salvador, mas também como uma localidade à margem da própria cidade. O produto era para ser consumido e utilizado pelos turistas. A lógica da intervenção do Pelourinho, assim como em vários outros projetos de recuperação de centros históricos, era tornar a área asséptica, extremamente limpa e vigiada.

No caso de Salvador, apesar de se manter à margem da cidade, uma vez que a população local se apropria muito pouco do Pelourinho, a 'contra-racionalidade baiana' insere, contra a vontade da gestão municipal e estadual, a sua própria vida: pessoas dormindo na rua, pedindo dinheiro, usando drogas, vendendo souvenires e corpos, afinal esta sempre foi a vida no Maciel. Outra mostra desta possibilidade de superar as normas impostas pelas ações do planejamento e mostrando que o corpo não transformado em estátua pode perverter a ordem estabelecida, em 2008, quando a secretária de Estado dos EUA, Condolezza Rice, visitou o Pelourinho, o Maciel emergiu das fachadas pintadas e, apesar de todo o aparato de segurança brasileiro e norte-americano, um menino, um corpo indócil, driblou todas as normas e pediu $R \$ 1,00$ para a secretária.

Entrevistando os novos usuários - os turistas - praticamente $100 \%$ deles reclamaram do lixo, do barulho, da abordagem dos vendedores, ou seja, a experiência 'cultural' é muito próxima da realidade de Salvador e, portanto, oposta à imagem e às lógicas que retiram a força os patrimônios da própria cidade. Mas este inclusão do Pelourinho na vida da própria cidade, não é o resultado de uma intervenção do planejamento e da gestão do território, mas sim uma apropriação a partir das brechas e das entranhas do processo de requalificação, refuncionalização e agora gentrificação do centro histórico de Salvador.

É preciso pensar novas formas de planejamento e gestão que incluam as singularidades, as temporalidades e as cotidianeidades locais, ampliando as possibilidades de realização da vida e da própria cidade. Planos menos funcionalistas e materialistas, incluindo os corpos, as vidas e os cotidianos.

Mas como fazer? A resposta está longe de ser alcançada, pois ainda existe uma contradição a ser superada, pois as ações do planejamento se inserem na normatização e no ordenamento do espaço, na cidade vista como território das normas e o cotidiano é a espontaneidade, é o que foge a norma, apensar de também ser a norma, o lugar é o espaço da cidade de realização cotidiana. O tempo do planejamento e da sua ação também está descompassado com o tempo da vida cotidiana, pois as decisões sobre a cidade aparecem sempre tomadas 
em cima dos prazos dos editais. Assim, as contradições entre o território e o lugar, entre a norma e espontaneidade, entre o tempo rápido e o tempo lento, e entre o corpo dócil e o corpo subversivo precisam de maiores estudos.

Mesmo com a repetição dos planos de recuperação e gestão das cidades históricas, ou daquelas com extenso acervo de patrimônios arquitetônicos, as cidades sempre serão maiores que isto, possibilitando sempre novos olhares ou olhares subversivos, bem como usos que pervertam a ordem estabelecida.

\section{REFERÊNCIAS}

COSTA PINTO, Luiz de Aguiar. Recôncavo: laboratório de uma experiência humana. In: BRANDÃO, M. A (Org.). Recôncavo da Bahia: sociedade e economia em transição. Salvador: Fundação Casa de Jorge Amado, 1998.

JEUDY, Henri-Pierre. Espelho das cidades. Rio de Janeiro: Casa da Palavra, 2005.

HENRIQUE, Wendel. A instalação da UFRB, a ação do Programa Monumenta e o turismo étnico na reestruturação urbana e no cotidiano de CachoeiraBA: notas preliminares de pesquisa. Geotextos, Salvador, v. 5, p. 89-112, 2009.

MONTEIRO LOBATO, José Bento. Cidades mortas. São Paulo: Brasiliense, 1972.

SANTOS, Milton. A rede urbana do Recôncavo. Salvador: UFBA; Imprensa Oficial, 1959.

Recebido em 06/09/2009

Aceito em 09/11/2009 